Supplement of Atmos. Chem. Phys., 21, 4381-4401, 2021

https://doi.org/10.5194/acp-21-4381-2021-supplement

(C) Author(s) 2021. CC BY 4.0 License.

(c) (i)
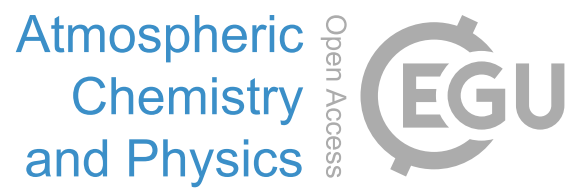

Supplement of

\title{
Drivers of the fungal spore bioaerosol budget: observational analysis and global modeling
}

Ruud H. H. Janssen et al.

Correspondence to: Ruud H. H. Janssen (ruud.janssen@tno.nl) and Colette L. Heald (heald@mit.edu)

The copyright of individual parts of the supplement might differ from the article licence. 
Table S1: global emissions, burden and lifetime for the population and statistical model for two sensitivity runs

\begin{tabular}{|l|l|l|l|l|}
\hline Emission scheme & Simulation & Emission (Tg year-1) & Burden (Gg) & Lifetime (days) \\
\hline Population model & DILFACT0.3 & 2.7 & 15.8 & 2.1 \\
\hline Statistical model & DILFACT0.3 & 2.9 & 12.0 & 1.4 \\
\hline Population model & RAINOUT0 & 3.4 & 25.6 & 2.9 \\
\hline Statistical model & RAINOUT0 & 3.7 & 20.0 & 2.1 \\
\hline
\end{tabular}

Table S2: normalization factors of the FBAP measurements for each campaign. We applied min-max normalization, which scales all values to a range between 0 and 1 .

\begin{tabular}{|l|l|}
\hline Campaign & Normalization factor \\
\hline Germany & $9.6 \times 10^{-3}$ \\
\hline Finland & 0.014 \\
\hline Colorado & 0.019 \\
\hline Ideas & 0.095 \\
\hline SEAC4RS & $3.6 \times 10^{-3}$ \\
\hline NAAMES 2015 & 0.15 \\
\hline NAAMES 2016 & 0.048 \\
\hline NAAMES 2017 & 0.12 \\
\hline
\end{tabular}




\section{Dayton, $\mathrm{OH}$}
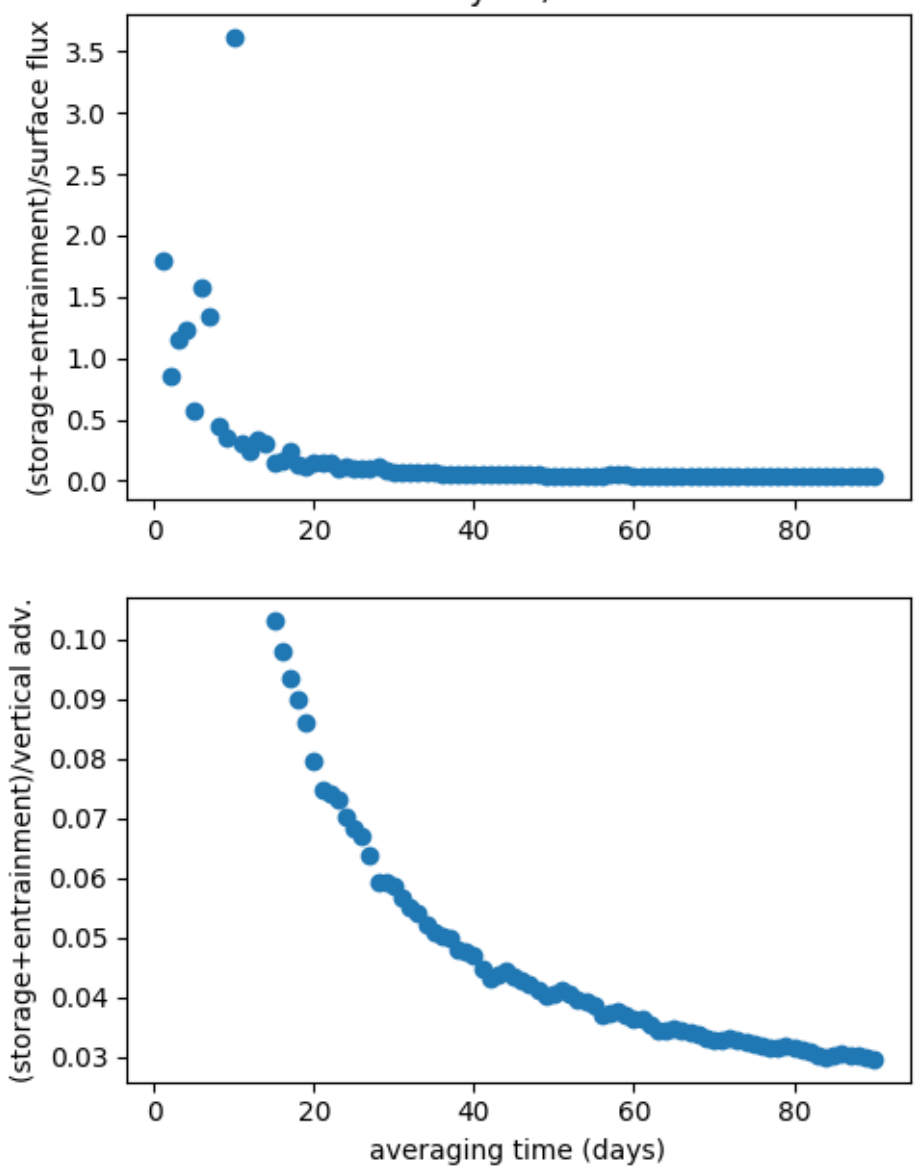

Figure S1: ratio of storage+entrainment vs. the net surface flux and vertical advection for different averaging times 


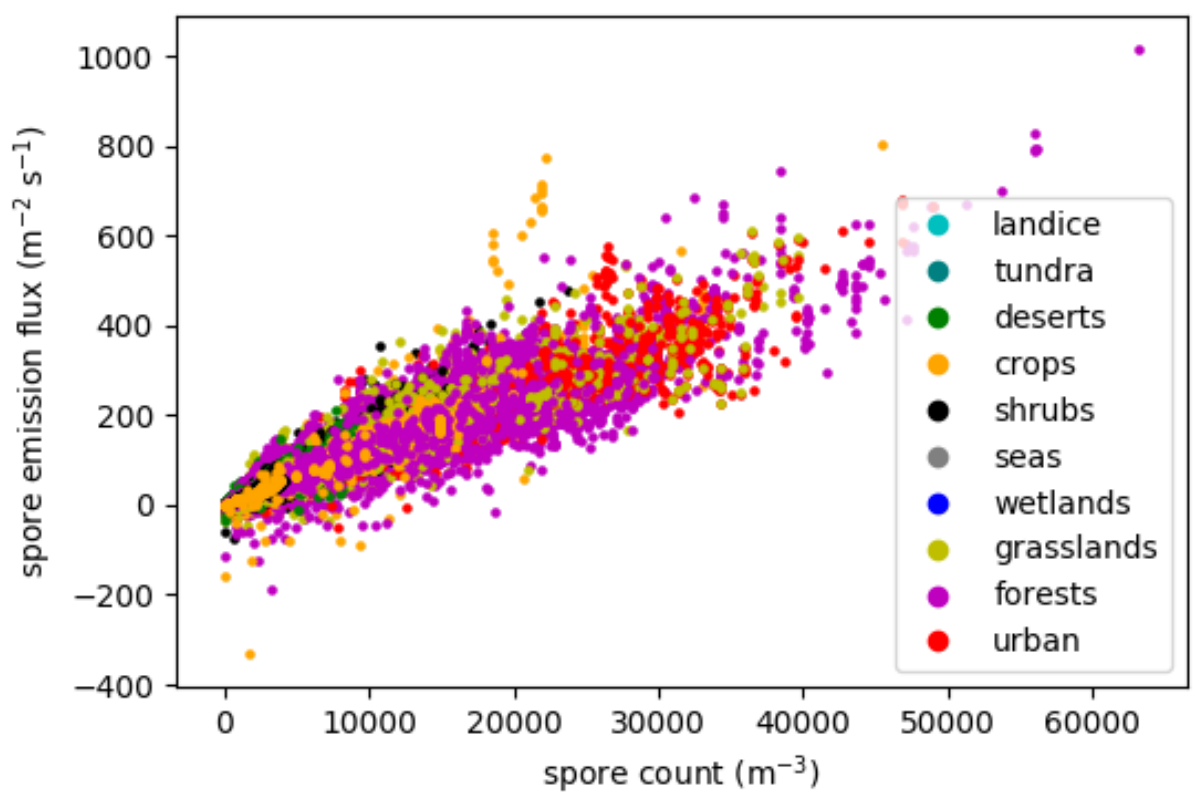

Figure S2: relationship between spore counts and derived emissions for different land use types. Each point represents a daily spore count at a single AAAAI station
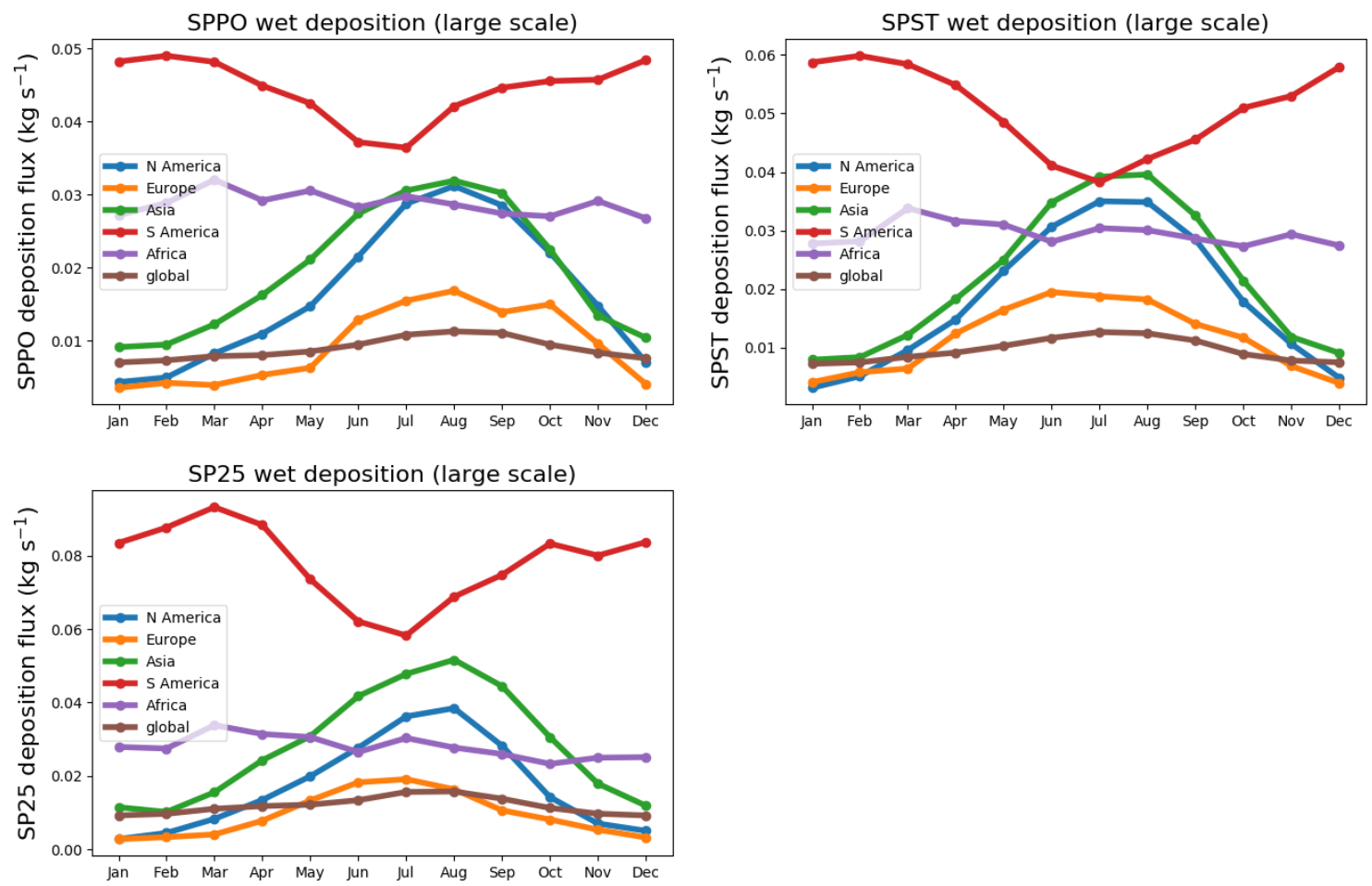

Figure S3: Seasonal cycles of fungal spore wet deposition in GEOS-Chem simulations for the statistical, the population and the HSO9 model. Note the different scales on the y-axis 

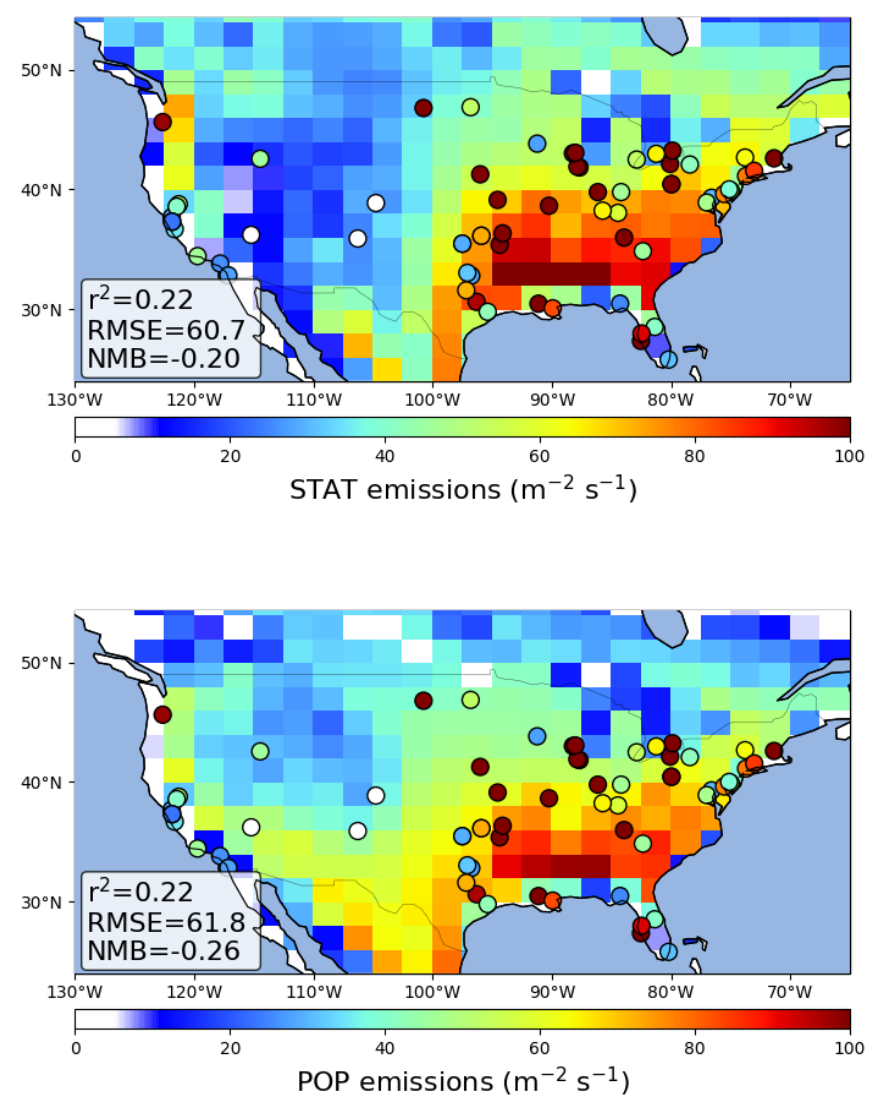

Figure S4: Comparison of GEOS-Chem simulated (CTRL simulation) emission fluxes of fungal spores to emission fluxes derived from AAAAl observations for the statistical model (top) and the population model (bottom). Statistics describing the comparisons are shown inset. 


\section{Germany}
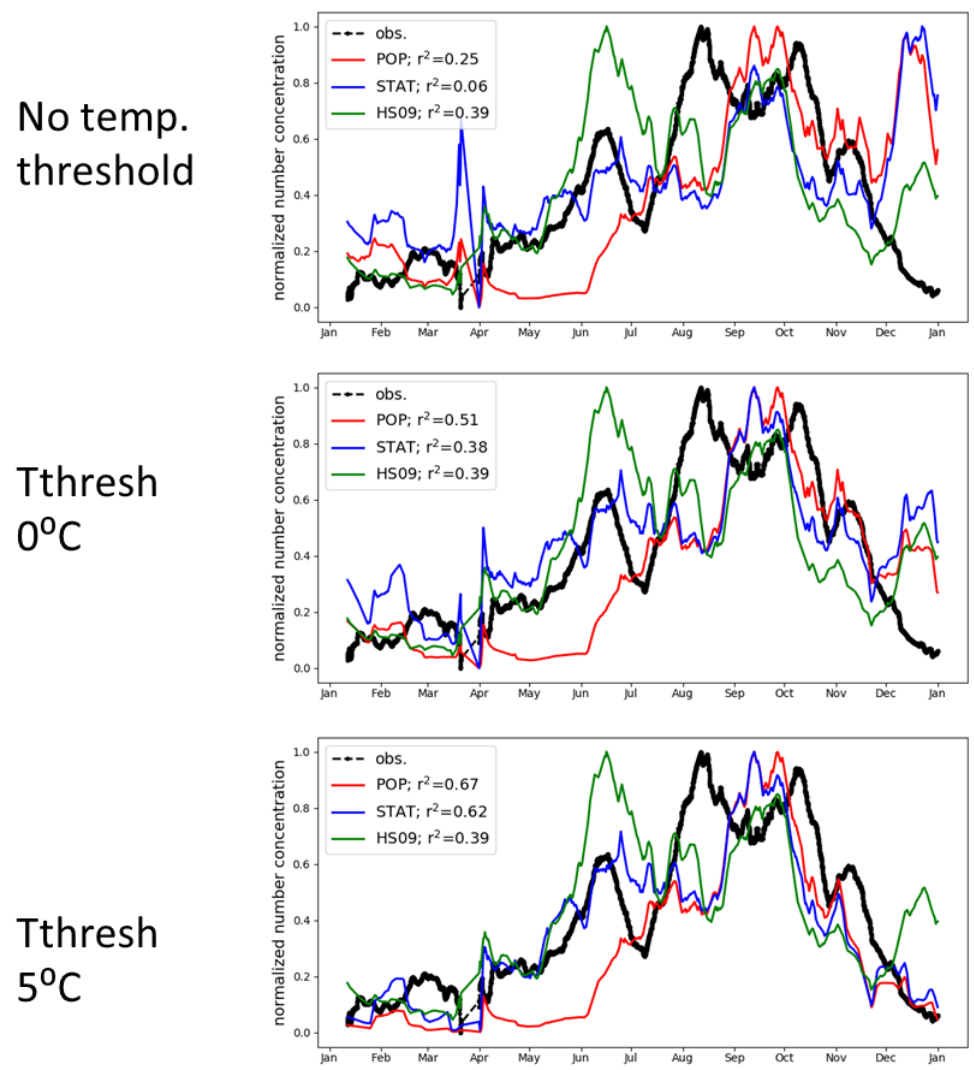

Finland
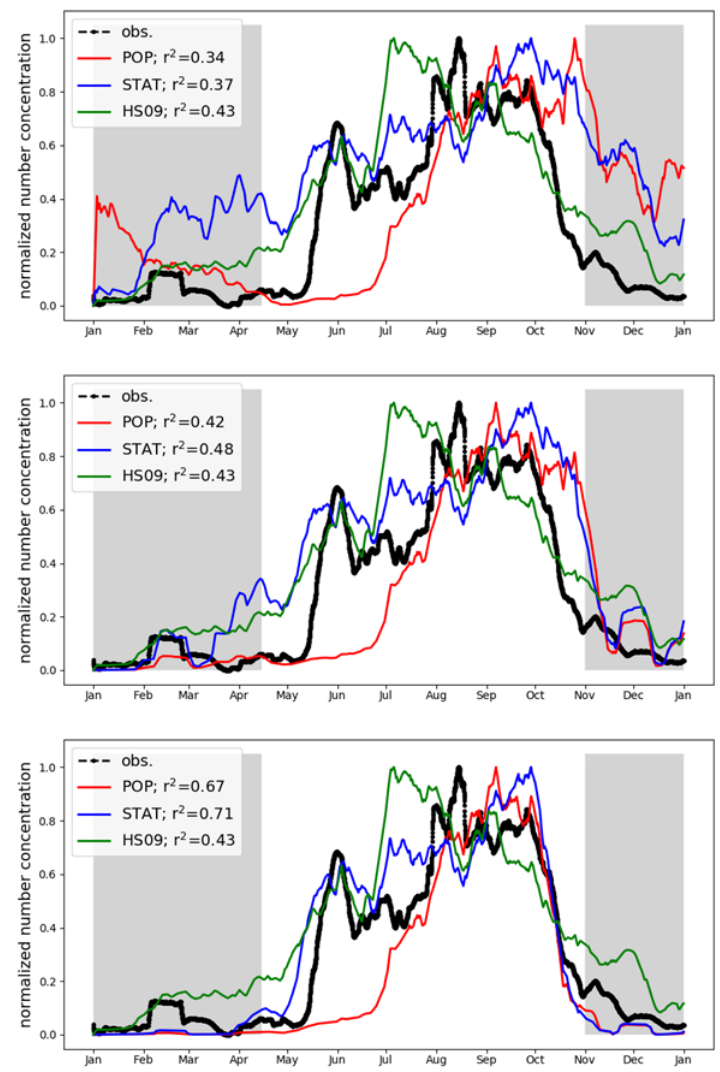

Figure S5: sensitivity to chosen temperature threshold of modeled spore concentrations at the sites in Germany and Finland. No temperature threshold (top), threshold of $0^{\circ} \mathrm{C}$ (middle) and threshold of $5^{\circ} \mathrm{C}$ (bottom) 